\title{
Complexity of coronary artery disease affects outcome of patients undergoing coronary artery bypass grafting with impaired left ventricular function
}

\author{
Giovanni Melina, MD, PhD, ${ }^{\mathrm{a}}$ Emiliano Angeloni, $\mathrm{MD},{ }^{\mathrm{a}}$ Umberto Benedetto, $\mathrm{MD}, \mathrm{PhD},{ }^{\mathrm{a}}$ \\ Francesco Monti, MD, ${ }^{\mathrm{b}}$ Antonino Roscitano, MD, ${ }^{\mathrm{a}}$ Roberto Serdoz, MD, ${ }^{\mathrm{b}}$ and Riccardo Sinatra, $\mathrm{MD}^{\mathrm{a}}$
}

Objective: To determine whether the SYNTAX score can predict the outcomes of patients with left ventricular dysfunction undergoing coronary artery bypass grafting.

\begin{abstract}
Methods: We studied a consecutive series of 191 patients (mean age, $67 \pm 10$ years) with a left ventricular ejection fraction of $40 \%$ or less who were undergoing isolated coronary artery bypass grafting. All patients were stratified according to their SYNTAX score, indicating coronary artery disease complexity: low, 0 to 22 ; intermediate, 23 to 32; and high, 33 or more. The primary outcome was all-cause mortality. Secondary outcomes included the late occurrence of major adverse cardiac and cerebrovascular events, left ventricular function, and New York Heart Association functional class.
\end{abstract}

Results: The mean SYNTAX score was $32 \pm 13$, and the mean preoperative left ventricular ejection fraction was $35 \% \pm 6 \%$. At a median follow-up of 43 months, the primary outcome had occurred in 46 of 191 patients $(24 \%)$. Kaplan-Meier analysis showed a survival of $81 \% \pm 15 \%$ for low, $77 \% \pm 7 \%$ for intermediate, and $53 \% \pm 7 \%$ for high coronary artery disease complexity $\left(\chi^{2}, 29.4 ; P=.001\right)$. The rate of major adverse cardiac and cerebrovascular events was significantly greater in patients with a SYNTAX score of 33 or more $(P=.002)$. Greater degrees of left ventricular ejection fraction improvement were found in patients with a SYNTAX score of 32 or less $(+15 \% \pm 10 \%$ vs $+4 \% \pm 11 \% ; P=.17)$ and translated into a better New York Heart Association functional class among patients with a lower SYNTAX score $(P=.01)$. Receiver operating characteristic curve analysis showed the SYNTAX score (area under the curve, $0.70 ; 95 \%$ confidence interval, $0.63-0.77$ ) to have the best predictive power for late mortality with respect to the preoperative left ventricular ejection fraction (area under the curve, 0.59; difference, $P=.04$ ) and incomplete revascularization (area under the curve, 0.55; difference, $P=.02$ ).

Conclusions: The results of the present study have shown a direct relationship between coronary artery disease complexity and late outcomes of patients with left ventricular dysfunction who are undergoing coronary artery bypass grafting. Additional studies are needed to confirm these findings. (J Thorac Cardiovasc Surg 2013;146:656-61)

Left ventricular (LV) dysfunction in patients with coronary artery disease $(\mathrm{CAD})$ is not always an irreversible process related to previous myocardial infarction, because LV function has been shown to improve substantially in many patients and can even normalize after coronary artery bypass grafting $(\mathrm{CABG}){ }^{1-4}$ The realization that a large proportion of patients with heart failure owing to CAD have viable, but dysfunctional, myocardium has led logically to attempts to resuscitate stunned or hibernating myocardium using revascularization techniques. ${ }^{5,6}$ This

From the Department of Cardiac Surgery, ${ }^{\text {a }}$ Ospedale Sant'Andrea, "Sapienza" University, Rome, Italy; and Department of Cardiology, ${ }^{\text {b }}$ Ospedale S. Pietro Fatebenefratelli, Rome, Italy.

Disclosures: Authors have nothing to disclose with regard to commercial support. Received for publication June 18, 2012; revisions received July 20, 2012; accepted for publication Aug 23, 2012; available ahead of print Sept 19, 2012.

Address for reprints: Giovanni Melina, MD, PhD, Department of Cardiac Surgery, Ospedale Sant'Andrea, "Sapienza" University, Via di Grottarossa 1035, Rome 00189, Italy (E-mail: gmelina@ospedalesantandrea.it).

0022-5223/\$36.00

Copyright $(2) 2013$ by The American Association for Thoracic Surgery

http://dx.doi.org/10.1016/j.jtcvs.2012.08.058 approach has been based on substantial, although largely anecdotal, evidence that revascularization, usually by CABG, can improve contractile function of viable, but dysfunctional, myocardium. ${ }^{7}$ A meta-analysis of observational studies suggested that revascularization might reduce mortality by $80 \%$ in patients with an extensive amount of viable myocardium but would have no effect in those without extensive viability. ${ }^{3,8}$ Recently, 2 randomized, controlled trials, the Surgical Treatment for Ischemic Heart Failure trial $^{9}$ and Heart Failure Revascularisation Trial, ${ }^{5}$ failed to show a substantial benefit from revascularization. In particular, the subgroup of patients with few viable segments appeared to benefit from CABG, the exact opposite of the previously cited observational data. ${ }^{3}$ In their recent editorial on this topic, Cleland and colleagues ${ }^{8}$ stated that this suggests that revascularization might be best reserved for patients with rather few viable segments, whether or not the function of these segments is impaired, if subtended by coronary lesions amenable to revascularization, to save what little surviving myocardium is left. 

Abbreviations and Acronyms
AUC = area under the curve
$\mathrm{CABG}=$ coronary artery bypass grafting
$\mathrm{CAD}=$ coronary artery disease
$\mathrm{LV}=$ left ventricular
$\mathrm{LVEF}=$ left ventricular ejection fraction
PCI = percutaneous coronary intervention
ROC $=$ receiver operating characteristic

Therefore, not only is restoring an appropriate blood supply to the stunned or hibernating myocardium a key factor for achieving postoperative LV functional recovery, but also the results of CABG in patients with LV dysfunction could rely on the CAD complexity. The SYNTAX score is an angiographic tool to measure the complexity of CAD. It has recently been shown to predict the outcome in patients undergoing percutaneous coronary intervention (PCI). ${ }^{10}$ Investigations testing the predictive power of the SYNTAX score on patients undergoing CABG surgery have not shown unequivocal results. ${ }^{10-16}$ To date, no similar studies have been published of using the SYNTAX score specifically for a subgroup of patients with LV dysfunction undergoing surgical revascularization.

The aim of the present investigation was to assess the predictive power of the SYNTAX score in patients with LV dysfunction due to $\mathrm{CAD}$ who were undergoing myocardial revascularization by $\mathrm{CABG}$.

\section{PATIENTS AND METHODS}

The Institutional Review Board of the University of Rome reviewed and approved the present study, and a waiver of consent was granted.

\section{Patients}

We studied a consecutive series of 191 patients amenable to CABG (mean age, $67 \pm 10$ years) with a LV ejection fraction (LVEF) of $40 \%$ or less at 1 institution from May 2004 to May 2010. All operations were performed at Ospedale Sant'Andrea, "Sapienza" University (Rome, Italy). The inclusion criterion was isolated on-pump CABG. The exclusion criteria were previous cardiac surgery, combined procedures, PCI within 6 months of surgery, and off-pump CABG.

The SYNTAX score algorithm, which has been previously described in full $^{10}$ (available from the SYNTAX score Web site: www.syntaxscore. com), was used to retrospectively score all coronary lesions deemed to have a percentage diameter stenosis of $50 \%$ or more, in vessels $1.5 \mathrm{~mm}$ or greater. All angiographic variables pertinent to SYNTAX score calculation were computed by 2 experienced interventional cardiologists (F.M., R.Ser.) on diagnostic angiograms obtained before the procedure. In the case of disagreement, the opinion of a third analyst (R.Sin.) was obtained, and the final decision was by consensus. The analysts were unaware of the procedural data and clinical outcomes. The final score was calculated on a patient basis from the individual lesion scores, which were saved in a dedicated database, and were not made available to the analysts until after study completion. The patients were divided into 3 groups according to the measured extent of CAD using their SYNTAX score to indicate CAD complexity: low, 0 to 22 ; intermediate, 23 to 32 ; and high, more than 33 .

\section{Operative Details}

All patients, after a full median sternotomy, underwent on-pump CABG using standard techniques. Cardiac arrest was obtained by antegrade cold blood cardioplegia, repeated every 15 minutes. The left internal mammary artery was always used to graft the left anterior descending artery, and revascularization was completed using saphenous vein grafts to the right coronary and left circumflex artery segments.

\section{Follow-up}

The data were prospectively collected and recorded in an electronic database, and clinical follow-up was completed with routine outpatient clinic visits. Patients who did not present at their follow-up visit were interviewed by telephone. All symptoms, mortality, and any complications that occurred during follow-up were recorded. The clinical and echocardiographic assessments were performed before $\mathrm{CABG}$ and at 6-month intervals postoperatively and then annually. At each visit, all patients underwent a complete M-mode, bidimensional, and Doppler transthoracic echocardiographic assessment using a Sonos 7500 system (Philips Medical Ultrasound; Philips Healthcare, DA Best, The Netherlands). All echocardiographic studies were reviewed in core laboratory and independently reviewed by 2 cardiologists. The LVEF was calculated using Simpson's biplane method.

\section{Statistical Analysis}

Statistical analysis was performed using the Statistical Package for Social Sciences, version 11.0 (SPSS, Chicago, Ill). Continuous data are expressed as the mean \pm standard deviation and categorical data as percentages. Comparisons were made using the 2 -sample $t$-test and the $\chi^{2}$ or Fischer exact test, respectively. Differences in continuous variables among the 3 groups of patients were calculated using the analysis of variance test.

Actuarial estimates of survival were made using the Kaplan-Meier method, and differences in time-related events were analyzed using the log-rank test. The survival time of a patient started at the point of surgery and ended at death (event) or the last follow-up visit (censoring).

The primary outcome was all-cause mortality during follow-up after revascularization. Secondary outcomes included a composite of all-cause mortality, myocardial infarction, cerebrovascular events, and repeat revascularization (MACCE), LV function, and New York Heart Association functional class. Mortality was defined as death from any cause, cardiac and noncardiac. Myocardial infarction was defined as cardiac enzyme levels 3 times or more the upper normal limit of normal and associated with the presence of ischemic symptoms or new electrocardiographic changes. A cerebrovascular accident was defined as stroke, transient ischemic attack, or coma.

The predictive power for late mortality of the SYNTAX score, preoperative LVEF, and completeness of revascularization was tested by receiver operating characteristic (ROC) curve analysis.

\section{RESULTS}

The baseline characteristics of the study population stratified by the SYNTAX score are listed in Table 1 . The SYNTAX score ranged from 1 to 42 (mean, $32 \pm 13$; median, 10). The LVEF ranged from $29 \%$ to $40 \%$ (mean, $35 \% \pm 6 \%$; median, $36 \%)$. Male gender was prevalent $(163 / 191,85 \%)$. The preoperative creatinine level was $1.4 \pm 1 \mathrm{mg} / \mathrm{dL}$, the mean logistic European System for Cardiac Operative Risk Evaluation was $19 \% \pm 10 \%$, and 48 of the 191 patients $(25 \%)$ underwent urgency or emergency surgery. The mean number of diseased vessels was $2.6 \pm 0.4$, and the mean number of anastomoses was $2.7 \pm 0.8$. The operative characteristics and postoperative complications are listed in Table 2. 
TABLE 1. Baseline clinical characteristics and risk factors

\begin{tabular}{|c|c|c|c|c|}
\hline \multirow[b]{2}{*}{ Variable } & \multicolumn{3}{|c|}{ SYNTAX score } & \multirow[b]{2}{*}{$P$ value } \\
\hline & $\begin{array}{c}\leq \mathbf{2 2} \\
(\mathbf{n}=\mathbf{3 2})\end{array}$ & $\begin{array}{c}>22 \text { but } \leq 32 \\
(n=60)\end{array}$ & $\begin{array}{c}>32 \\
(n=99)\end{array}$ & \\
\hline Age (y) & $66 \pm 9$ & $65 \pm 11$ & $69 \pm 10$ & .19 \\
\hline Male gender & $27(84)$ & $53(88)$ & $83(83)$ & .84 \\
\hline Hypertension & $32(100)$ & $51(85)$ & $88(88)$ & .25 \\
\hline Diabetes & $13(41)$ & $27(45)$ & $51(51)$ & .21 \\
\hline Hyperlipidemia & $25(78)$ & $43(72)$ & 77 (77) & .27 \\
\hline COPD & $7(22)$ & $11(18)$ & $24(24)$ & .62 \\
\hline History of smoking & $18(56)$ & $34(57)$ & $56(56)$ & .57 \\
\hline Previous stroke & $4(13)$ & $7(12)$ & $14(14)$ & .62 \\
\hline Recent MI & $20(63)$ & $34(57)$ & $66(66)$ & .66 \\
\hline Creatinine $(\mathrm{mg} / \mathrm{dL})$ & $1.2 \pm 0.3$ & $1.4 \pm 1$ & $1.5 \pm 1$ & .32 \\
\hline Mean LVEF (\%) & $35 \pm 7$ & $34 \pm 6$ & $35 \pm 6$ & .79 \\
\hline NYHA III/IV & $9(28)$ & $18(30)$ & $28(28)$ & .78 \\
\hline Urgency & $7(22)$ & $15(25)$ & $26(26)$ & .25 \\
\hline Left main stenosis & $10(31)$ & $21(35)$ & $39(39)$ & .10 \\
\hline Logistic euroSCORE & $16 \pm 7$ & $19 \pm 8$ & $21 \pm 11$ & .23 \\
\hline
\end{tabular}

After a median follow-up of 43 months $(95 \%$ confidence interval, 39-58), all-cause mortality was $24 \%$ (46/191). A tendency was found toward lower CAD complexity among survivors than among patients who died late postoperatively (SYNTAX score, $33 \pm 12$ vs $36 \pm 12$, respectively; $P=.16)$. The rate of myocardial infarction, cerebrovascular accidents, and repeat revascularization was $2 \%(4 / 191)$, $2 \%(4 / 191)$, and $5 \%(9 / 191)$, respectively. The cumulative rate of MACCE was 33\% (63/191); overall, 92\% (175/191) of patients underwent complete revascularization. The individual prevalence of the outcomes stratified by the SYNTAX score groups is listed in Table 3.

At follow-up, the mean LVEF improvement was $+8 \% \pm$ $21 \%$, and the mean LVEF at follow-up was $43 \% \pm 22 \%$ (difference from preoperatively, $P=.03$ ). Patients with a SYNTAX score of 32 or less had the greatest degrees of LVEF improvement $(+15 \% \pm 10 \%$ vs $+4 \% \pm 11 \%$ in those with a SYNTAX score of $\geq 33 ; P=.12$ ). This translated into a better New York Heart Association functional class (Table 3).

The rates of both all-cause mortality $(P=.004)$ and MACCE $(P=.002)$ were significantly greater in patients with high CAD complexity (Table 3 ). The mortality rate was slightly greater at $25 \%$ (4/16) for patients with incomplete revascularization versus $22 \%(39 / 175)$ for patients with complete revascularization $(P=.11)$.

The Kaplan-Meier analysis showed a statistically significant difference in survival among the 3 groups (Figure 1). At 5 years, cumulative survival was $81 \% \pm 15 \%$ for those with low, $77 \% \pm 7 \%$ for those with intermediate, and $53 \% \pm 7 \%$ for those with high CAD complexity, (model $\chi^{2}, 29.4 ; P=.001$ ).
TABLE 2. Perioperative variables stratified by SYNTAX score risk groups

\begin{tabular}{lcccc}
\hline & \multicolumn{3}{c}{ SYNTAX score } & \\
\cline { 2 - 4 } \multicolumn{1}{c}{ Variable } & $\begin{array}{c}\leq \mathbf{2 2} \\
(\mathbf{n}=\mathbf{3 2})\end{array}$ & $\begin{array}{c}>\mathbf{2 2} \text { but } \leq \mathbf{3 2} \\
(\mathbf{n}=\mathbf{6 0})\end{array}$ & $\begin{array}{c}>\mathbf{3 2} \\
(\mathbf{n}=\mathbf{9 9})\end{array}$ & $\begin{array}{c}\boldsymbol{P} \\
\text { value }\end{array}$ \\
\hline CPB time (min) & $112 \pm 27$ & $121 \pm 56$ & $118 \pm 59$ & .63 \\
Aortic crossclamp time (min) & $73 \pm 27$ & $84 \pm 33$ & $82 \pm 39$ & .41 \\
Grafts (n) & $2.7 \pm 0.7$ & $2.6 \pm 1.1$ & $2.7 \pm 0.9$ & .74 \\
IABP & $6(19)$ & $13(22)$ & $26(26)$ & .24 \\
Incomplete revascularization & $2(6)$ & $5(8)$ & $9(9)$ & .25 \\
Postoperative complications & & & & \\
$\quad$ AKI & $6(19)$ & $12(20)$ & $22(22)$ & .74 \\
MI & $1(3)$ & $3(5)$ & $7(7)$ & .16 \\
CVA & $2(6)$ & $6(10)$ & $12(12)$ & .18 \\
Mortality & $2(6)$ & $5(8)$ & $15(15)$ & .11 \\
\hline Da
\end{tabular}

Data presented as mean \pm standard deviation or $\mathrm{n}(\%) . A K I$, Acute kidney injury; $C P B$, cardiopulmonary bypass; $C V A$, cerebrovascular accident; IABP, intra-aortic balloon pump; $M I$, myocardial infarction.

The ROC curve analysis showed good accuracy for the SYNTAX score in predicting late mortality. The area under the curve (AUC) was 0.70 (95\% confidence interval, $0.63-$ $0.77 ; P=.0001)$; the sensitivity and specificity was $63 \%$ and $71 \%$, respectively, for a SYNTAX score greater than 35. A comparison of the ROC curves (Figure 2) showed the SYNTAX score to have the best predictive power for late mortality compared with preoperative LVEF (AUC, 0.59 ; difference, $P=.04$ ) and incomplete revascularization (AUC, 0.55; difference, $P=.02$ ).

\section{DISCUSSION}

The present study has shown a direct relationship between CAD complexity, measured using the SYNTAX score, and survival late after surgical revascularization in patients with LV dysfunction due to ischemic heart disease. In addition, significantly worse outcomes were found in

TABLE 3. Postoperative outcome stratified by SYNTAX score risk groups

\begin{tabular}{lcccc}
\hline & \multicolumn{3}{c}{ SYNTAX score } & \\
\cline { 2 - 4 } \multicolumn{1}{c}{ Variable } & $\begin{array}{c}\leq \mathbf{2 2} \\
(\mathbf{n}=\mathbf{3 2})\end{array}$ & $\begin{array}{c}>\mathbf{2 2} \text { but } \leq \mathbf{3 2} \\
(\mathbf{n}=\mathbf{6 0})\end{array}$ & $\begin{array}{c}>\mathbf{3 2} \\
(\mathbf{n}=\mathbf{9 9})\end{array}$ & $\begin{array}{c}\boldsymbol{P} \\
\text { value }\end{array}$ \\
\hline Follow-up (mo) & & & & .37 \\
$\quad$ Median & 43 & 42 & 43 & \\
$\quad$ 95\% CI & $38-53$ & $39-59$ & $30-55$ & \\
Mean LVEF & $+15 \pm 10$ & $+10 \pm 10$ & $+4 \pm 11$ & .10 \\
$\quad$ improvement (\%) & & & & \\
NYHA III/IV & $2(6)$ & $5(8)$ & $19(19)$ & .04 \\
MI & $1(3)$ & $1(2)$ & $2(2)$ & .66 \\
Repeat revascularization & $1(3)$ & $2(3)$ & $6(6)$ & .12 \\
CVA & $1(3)$ & $2(3)$ & $1(1)$ & .74 \\
Mortality & $2(6)$ & $11(18)$ & $33(33)$ & .004 \\
Cumulative MACCE & $5(16)$ & $16(27)$ & $42(42)$ & .002 \\
\hline
\end{tabular}

$C I$, Confidence interval; $C V A$, cerebrovascular accident; $L V E F$, left ventricular ejection fraction; NYHA, New York Heart Association; MACCE, major adverse cardiac and cerebrovascular events; $M I$, myocardial infarction. 


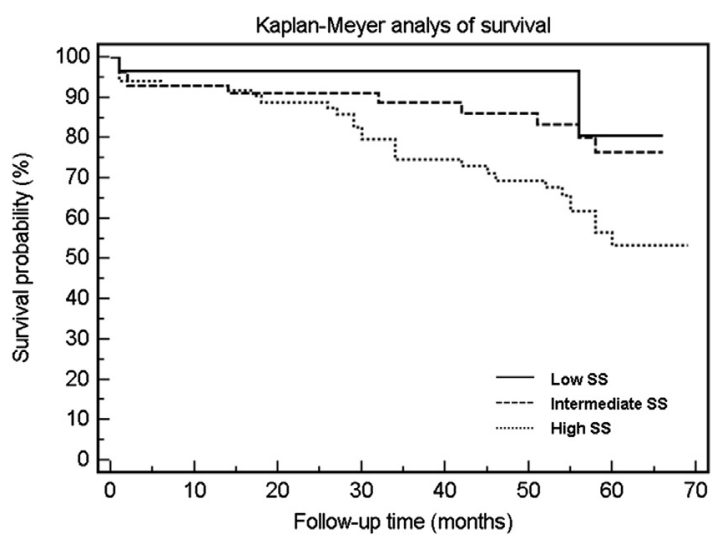

Patients at risk

$\begin{array}{llllllll}\text { Low SS } & 32 & 22 & 22 & 19 & 14 & 12 & 7 \\ \text { Intermediate SS } & 60 & 48 & 31 & 25 & 18 & 11 & 9 \\ \text { High SS } & 99 & 79 & 71 & 66 & 57 & 41 & 27\end{array}$

FIGURE 1. Kaplan-Meier survival analysis stratified by SYNTAX score (SS) risk groups.

terms of the incidence of MACCE, LV functional recovery, and New York Heart Association functional class in those patients with high CAD complexity.

$\mathrm{CAD}$ is the most common substrate for heart failure, and it is calculated to affect more than 20 million people in Europe and the United States. ${ }^{9,17}$ Atherosclerosis, LV systolic dysfunction, and heart failure are all progressive diseases, and it is logical to believe that treatment, including medical and surgical options, directed at these targets should retard the progression of heart failure, reducing morbidity and prolonging life expectancy. ${ }^{8}$

According to the most recent guidelines, $\mathrm{CABG}$ for patients presenting with $\mathrm{LV}$ dysfunction due to CAD is indicated if they have symptoms of angina and/or complex CAD. ${ }^{18}$ Furthermore, an angiographic method to assess CAD complexity, the SYNTAX score, has recently been developed for patients undergoing PCI. ${ }^{19}$

This method was then applied in a prospective randomized trial to compare patients with de novo 3-vessel disease or left main disease undergoing contemporary bypass surgery and PCI with drug-eluting stents. ${ }^{20}$ In that setting, SYNTAX score has been found to significantly predict the outcomes after PCI but, to date, has failed to demonstrate a similar relationship among those undergoing $\mathrm{CABG} .{ }^{21}$

To date, no other studies have used the SYNTAX score ${ }^{10-15}$ to focus on patients with LV dysfunction specifically. Such patients represent about $20 \%$ of those scheduled for CABG. In these patients, the anticipated benefit of coronary surgery might result from restoration of the blood supply by revascularization of areas of myocardium stunned or hibernating, ultimately leading to LV functional recovery. In the present series, as expected, the beneficial effect of CABG translated into a statistically significant improvement in LV function, which involved the whole cohort.

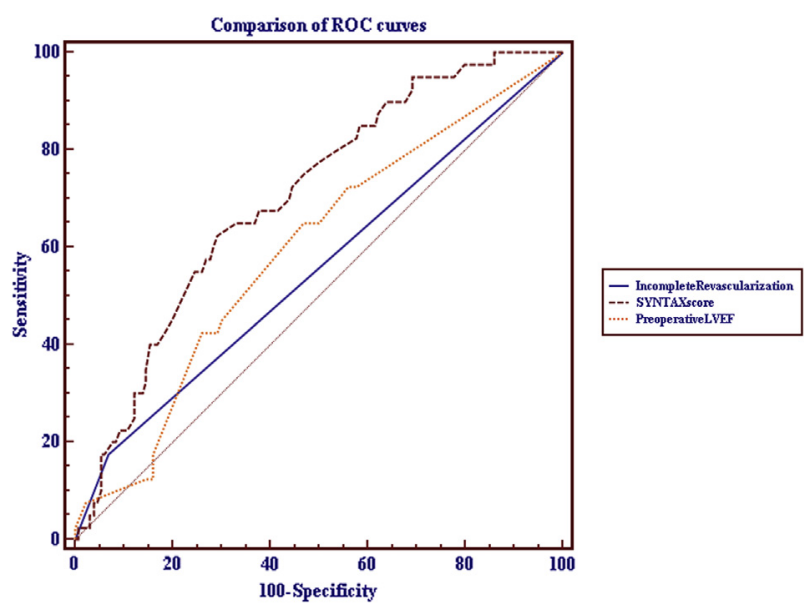

FIGURE 2. Predictive power analysis: comparison of receiver operating characteristic (ROC) curves of SYNTAX score, preoperative left ventricular ejection fraction $(L V E F)$, and incompleteness of revascularization.

The preoperative evaluation of patients with LV dysfunction amenable to CABG includes symptoms and myocardial viability but not the quality of the target vessels. ${ }^{1,18}$ It has recently been shown that those with high CAD complexity benefit more from coronary surgery than from $\mathrm{PCI}^{21}$ or hybrid coronary revascularization. ${ }^{22}$ In addition, the same investigation $^{21}$ showed that, unlike PCI patients, the SYNTAX score did not influence the incidence of adverse outcomes in the CABG population during a 12-month follow-up period.

In contrast, our study, which focused on a different population of patients with LV dysfunction due to CAD, found that the greater the SYNTAX score, the worse the outcome for both MACCE and mortality at a median follow-up of 43 months. These differences among the 3 groups started to show statistical significance at 18 to 20 months postoperatively.

A recent report ${ }^{23}$ on the effect of CAD complexity on the outcomes of CABG showed similar results in terms of MACCE but not for early and late mortality. The different population analyzed might have accounted for the latter finding. It could also be because patients with a high preoperative SYNTAX score tend to develop more aggressive CAD, especially over time, as in the present investigation.

The present finding of better survival among patients with better coronary vessels (lower SYNTAX score) suggests that revascularization of stunned/hibernating myocardium is more effective when performed on good quality vessels, regardless of regional and global ventricular function. In addition, it can be hypothesized that the greater blood flow provided by better coronary arteries might enhance restoration of metabolic imbalances, resulting, finally, in better myocardial performance, including functional class improvement, such as was seen in our study. 
The Surgical Treatment for Ischemic Heart Failure trial, comparing the strategy of medical therapy alone with that of medical therapy plus CABG for patients with LV dysfunction, did not show a significant difference between the 2 treatments in all-cause mortality, ${ }^{9}$ and differences between groups were found (in favor of CABG) with respect to the rate of death from cardiovascular causes. ${ }^{9}$ Finally, the study results were unable to determine a standard-of-care for patients with CAD and LV dysfunction.

We believe that measuring the quality of the vessels amenable to CABG using a quantitative analysis would provide more information about the strategy to undertake. Patients from the present study were divided into 3 groups according to their SYNTAX score and analyses performed accordingly. The stratification then included a low-, intermediate-, and high-risk score calculated from the original study by the SYNTAX investigators. ${ }^{10}$ Patients with the highest scores of CAD complexity had the worst outcomes, in terms of both primary and secondary endpoints after CABG. Because the rate of revascularization completeness in the present study was similar among the 3 groups and to that reported in previous investigations, our findings could account for the rates of patients who do not benefit from CABG and make these patients similar to the medically treated ones, as shown in the previously cited series. It is possible that this might be because even if viable myocardium is present, the results of the surgical procedure are somehow not as effective because of the high CAD complexity. In addition, from the ROC curve analysis, the SYNTAX score showed the best predictive power (AUC, 0.70) for late mortality compared with both the LVEF (AUC, 0.59 ) and the completeness of revascularization (AUC, 0.55). The incidence of myocardial infarction, cerebrovascular accidents, and repeat revascularization was similar among the 3 groups, although a greater rate of new revascularization procedures was seen among patients with a SYNTAX score greater than 32 . The statistical difference in MACCE incidence seen in our analysis was related to the greater mortality rates and repeat revascularization procedures observed in patients with high CAD complexity. We believe that the evaluation of CAD complexity as measured by the SYNTAX score can be helpful in these settings, and studies that relate the amount of underperfused myocardium (cardiac magnetic resonance imaging, stress echocardiography, or myocardial scintigraphy) to the SYNTAX score might add more information to support this investigation.

\section{Study Limitations}

One limitation of the present study was its retrospective nature and the small number of patients investigated. In addition, the SYNTAX score was applied to patients undergoing CABG, although it was originally developed for patients scheduled for PCI. ${ }^{19}$ Another limitation was the lack of data on myocardial viability and intraoperative measurement of graft and/or coronary flow. This would definitively strengthen our findings; however, such data were available only for a small number of patients, and thus statistical analysis was not possible.

\section{CONCLUSIONS}

We have shown that the greater the complexity of CAD, the worse the late outcome after CABG in patients with LV dysfunction. Additional studies, with a larger number of patients, are required to confirm these findings and their clinical effect.

We thank Drs Tommaso Hinna Danesi, Roberta di Bartolomeo, and Simone Refice for their invaluable work during the selection of the patients to be included in the present study. They were also involved in the SYNTAX score calculation process. We are also grateful to Dr Andrea Lechiancole, who helped us in the followup of the patients who were interviewed by telephone because they could not attend the outpatient clinic.

\section{References}

1. Bonow RO, Maurer G, Lee KL, Holly TA, Binkley PF, Desvigne-Nickens P, et al. Myocardial viability and survival in ischemic left ventricular dysfunction. $N$ Engl J Med. 2011;364:1617-25.

2. Dilsizian V, Bonow RO. Current diagnostic techniques of assessing myocardial viability in hibernating and stunned myocardium. Circulation. 1993;87:1-20; erratum, Circulation. 1993;87:2070.

3. Allman KC, Shaw LJ, Hachamovitch R, Udelson JE. Myocardial viability testing and impact of revascularization on prognosis in patients with coronary artery disease and left ventricular dysfunction: a meta-analysis. J Am Coll Cardiol. 2002; 39:1151-8.

4. Elefteriades JA, Tolis G Jr, Levi E, Mills LK, Zaret BL. Coronary artery bypass grafting in severe left ventricular dysfunction: excellent survival with improved ejection fraction and functional state. J Am Coll Cardiol. 1993;22:1411-7.

5. Cleland JG, Calvert M, Freemantle N, Arrow Y, Ball SG, Bonser RS, et al. The Heart Failure Revascularisation Trial (HEART). Eur J Heart Fail. 2011;13: 227-33.

6. Pitt M, Lewis ME, Bonser RS. Coronary artery surgery for ischemic heat failure: risks, benefits, and the importance of assessment of myocardial viability. Prog Cardiovasc Dis. 2001;43:373-86.

7. Cleland JGF, Freemantle N, Ball SG, Bonser RS, Camici P, Chattopadhyay S, et al. The Heart Failure Revascularization Trial (HEART): rationale, design and methodology. Eur J Heart Fail. 2003;5:295-303.

8. Cleland JGF, Freemantle N. Revascularization for patients with heart failure. Inconsistency between theory and practice. Eur J Heart Fail. 2011;13: 694-7.

9. Velazquez EJ, Lee KL, Deja MA, Jain A, Sopko G, Marchenko A, et al. Coronary-artery bypass surgery in patients with left ventricular dysfunction. $N$ Engl J Med. 2011;364:1607-16.

10. Mohr FW, Rastan AJ, Serruys PW, Kappetein AP, Holmes DR, Pomar JL, et al. Complex coronary anatomy in coronary artery bypass graft surgery: impact of complex coronary anatomy in modern bypass surgery? Lessons learned from the SYNTAX trial after two years. J Thorac Cardiovasc Surg. 2011;141:130-40.

11. Chakravarty T, Buch MH, Naik H, White AJ, Doctor N, Schapira J, et al. Predictive accuracy of SYNTAX score for predicting long-term outcomes of unprotected left main coronary artery revascularization. Am J Cardiol. 2011;107: 360-6.

12. Park DW, Kim YH, Yun SC, Song HG, Ahn JM, Oh JH, et al. Complexity of atherosclerotic coronary artery disease and long-term outcomes in patients with unprotected left main treated with drug-eluting stents or coronary artery bypass grafting. J Am Coll Cardiol. 2011;57:2152-9.

13. Garg S, Sarno G, Garcia-Garcia HM, Girasis C, Wykrzykowska J, Dawkins KD, et al. A new tool for the risk stratification of patients with complex coronary 
artery disease: the clinical SYNTAX score. Circ Cardiovasc Interv. 2010;3: $317-26$.

14. Lemesle G, Bonello L, de Labriolle A, Steinberg DH, Roy P, Pinto Slottow TL, et al. Prognostic value of the SYNTAX score in patients undergoing coronary artery bypass grafting for three-vessel coronary artery disease. Catheter Cardiovasc Interv. 2009;73:612-7.

15. Capodanno D, Capranzano P, Di Salvo ME, Caggegi A, Tomasello D, Cincotta G, et al. Usefulness of SYNTAX score to select patients with left main coronary artery disease to be treated with coronary artery bypass graft. J Am Coll Cardiol Interv. 2009;2:731-8.

16. Birim O, van Gameren M, Bogers A, Serruys PW, Mohr FW, Kappetein AP. Complexity of coronary vasculature predicts outcome of surgery for left main disease. Ann Thorac Surg. 2009;87:1097-105.

17. Gheorghiade M, Sopko G, De Luca L, Velazquez EJ, Parker JD, et al. Navigating the crossroads of coronary artery disease and heart failure. Circulation. 2006; 114:1202-13.

18. Wijns W, Kolh P, Danchin N, Di Mario C, Falk V, Folliquet T, et al. Guidelines on myocardial revascularization:the Task Force on Myocardial Revascularization of the European Society of Cardiology (ESC) and the European Association for Cardio-Thoracic Surgery (EACTS). Eur Heart J. 2010;31:2501-55.
19. Sianos G, Morel MA, Kappetein AP, Morice MC, Colombo A, Dawkins K, et al The SYNTAX Score: an angiographic tool grading the complexity of coronary artery disease. EuroIntervention. 2005;1:219-27.

20. Ong AT, Serruys PW, Mohr FW, Morice MC, Kappetein AP, Holmes DR Jr, et al The SYnergy between percutaneous coronary intervention with TAXus and cardiac surgery (SYNTAX) study: design, rationale, and sign-in phase. Am Heart J. 2006;151:1194-204.

21. Serruys PW, Morice MC, Kappetein AP, Colombo A, Holmes DR, Mack MJ, et al, SYNTAX Investigators. Percutaneous coronary intervention versus coronary artery bypass grafting for severe coronary artery disease. $N$ Engl $\mathrm{J} \mathrm{Med}$. 2009;360:961-72.

22. Leacche M, Byrne JG, Solenkova NS, Reagan B, Mohamed TI, Fredi JL, et al; SYNTAX Investigators. Comparison of 30-day outcomes of coronary artery bypass grafting surgery versus hybrid coronary revascularization stratified by SYNTAX and euroSCORE. J Thorac Cardiovasc Surg. Epub 2012 Apr 25.

23. Carnero-Alcazar M, Maroto Castellanos LC, Silva Guisasola JA, Cobiella Carnicer J, Alswies A, Fuentes Ferrer ME, et al. SYNTAX score is associated with worse outcomes after off-pump coronary artery bypass grafting surgery for three-vessel or left main complex coronary disease. J Thorac Cardiovasc Surg. 2011;142:e123-32. 